\title{
Application of Rubrics in the Classroom: A Vital Tool for Improvement in Assessment, Feedback and Learning
}

\author{
Faieza Chowdhury ${ }^{1}$ \\ ${ }^{1}$ School of Business Studies, Southeast University, Dhaka, Bangladesh \\ Correspondence: Faieza Chowdhury, Southeast University, Banani, Dhaka 1213, Bangladesh. Tel: 550-341-2528. \\ E-mail: chowdhury.faieza@gmail.com
}

Received: August 26, 2018

doi:10.5539/ies.v12n1p61
Accepted: September 30, $2018 \quad$ Online Published: December 28, 2018

URL: https://doi.org/10.5539/ies.v12n1p61

\begin{abstract}
Teaching is filled with spirited debate about the best practices for improving students' learning and performance. Today, educators from different parts of the world are supporting the use of rubrics as an instructional tool and highlighting the enormous contributions that rubrics can make in the teaching-learning paradigm. A rubric is a useful grading tool which can help instructors to grade students' work in a more consistent, reliable and unbiased manner. A well-designed rubric can help students to identify their strengths and weaknesses and be more objective about their own quality of work. Although some studies have examined the benefits of rubrics on student performance levels; nevertheless, research on rubrics is still at an early stage. In this paper we will explore what a rubric is, the different types of rubrics that can be utilized in the classroom and the process of constructing a rubric. We will also discuss how the application of rubrics in teaching can help educators to improve student learning and provide more effective feedback on student performance.
\end{abstract}

Keywords: performance feedback, rubrics, student assessment, student learning

\section{Introduction}

The word "rubric" first originated in the mid-fifteenth century from the work of Christian monks who reproduced sacred literature, with each major section of the book headed in large red letters. The Latin word for red is rubric; hence, the headings of the major sections of the book were called rubrics. However, over the last few decades, educators have given a new meaning to the word and use 'rubric' to describe the rules that guide their evaluation of their students' work or performance.

Rubrics are useful grading tools that add reliability, validity and transparency to assessments. They are often used to increase transparency in assessments and to decrease subjectivity (Silvestri \& Oescher, 2006). They can be used daily in the classroom for descriptive writings, course projects, oral presentations, etc. A well-designed rubric is one that helps instructors not only to judge students' work effectively but also help students acquire certain skills and knowledge.

Typically, teachers do not use rubrics to assess short-answer tests or for scoring test results such as multiple-choice exams or true/false. Rubrics are mainly used to judge students' skills in performance-based tests, such as writing a persuasive essay on a given topic. Performance tests are intended to measure student mastery of certain types of skills that educators regard as worth learning and promoting.

Typically, most teachers do not express their standards of assessment to the students. Teachers often expect that students somehow will know how to write an excellent assignment all by themselves. However, this assumption often leads to disappointment when teachers later realize that students are underperforming or getting very poor grades. Rubrics can help instructors to clearly convey their expectations to the students by providing evaluative criteria for use in grading. With the help of rubrics, students can understand what level of work is considered good, very good, excellent or bad. A well-designed rubric can also help students by delivering constructive feedback about their common mistakes and by providing further information about how to improve their work. Studies by some researchers have illustrated the instructional benefits of using rubrics. These researchers have shown that the application of rubrics in the classroom eventually leads to improvements in student learning and overall performance. Moreover, several studies have indicated that rubrics can make assessments more reliable and transparent (Jonsson \& Svingby, 2007; Penny, Johnson, \& Gordon, 2000; Silvestri \& Oescher, 2006; Wolf \& 
Stevens, 2007).

Some teachers embrace rubrics and consider them as incredible tools for communicating expectations and grading students' written work. However, some critics complain that rubrics are rigid, unworkable and do a disservice to student writing. According to these critics, rubrics can result in a standardized measurement of student tasks. Wilson (2007), suggest that writing offers its own set of limitations, hence teachers should examine each piece of writing individually. Kohn (2006) states that rubrics should never be utilized as an instructional tool because this can result in student writing with less, rather than more, depth of thought.

The use of rubrics in higher education is comparatively recent; hence, a key question that many educators often ask before using them in their class is, "Can rubrics used as an instructional tool enhance student learning and achievement?" The answer to this question remains inconclusive. Nevertheless, most educators do agree that rubrics expedite the grading process and make grading seem fairer to students.

Rubrics can be used to assess a variety of student tasks, such as oral presentations, critical thinking, class participation, literature reviews, reflective writings, projects, etc. Moreover, most students also tend to agree that rubrics are useful in preparing assignments. When students are provided with rubrics along with their assignments, they have a clear understanding of what specific criteria they need to fulfill in order to achieve a particular grade or point value. Rubrics are useful to students in giving them a clear understanding of what is expected of them. Many studies have also proven that rubrics improve students' quality of work and thus enhance learning.

Although some previous studies provided empirical evidence of how the application of rubrics can enhance student learning, very few of them examined the basic concept of 'rubric', its construction process and its usage in the classroom. This paper seeks to fill this gap in the literature and to make instructors aware of how to construct a simple rubric for their class and the enormous benefits of using rubrics in class to enhance student learning.

\section{What is a Rubric?}

A rubric is a scoring tool that lays out the expectations of a task or assignment across 3 to 5 levels of performance. Rubrics can be used to state standards, instructional goals and objectives for the type of performances that students should be able to achieve while completing a task. Instructors use rubrics to divide assignments or tasks into different component parts, with a detailed description of each component reflecting what constitutes acceptable or unacceptable levels of performance.

Instructors can construct various models of rubrics and use rubrics in their classroom for different purposes; however, rubrics are not suitable for all types of tasks. For example, they are not suitable in assessing test items where there is one specific, clear, correct answer.

Here we have provided a list of indicators that can help instructors to understand when rubrics need to be utilized in the classroom:

- The instructor graded all the papers but later he or she had doubts that some of the papers may have been graded differently compared to some other papers in the stack.

- The instructor has a large number of papers that needs to be corrected within a short time period. The instructor is worried, as he or she is taking more time to correct each paper than he or she expected and thus may fail to meet the deadline for grade submission.

- The instructor is writing the same comment on every assignment that he or she is checking, despite the fact that the quality of each assignment varies significantly.

- The instructor is disappointed with class performance because most of the students failed to complete the assignment given to them and scored very low marks.

- Students often complain to the instructor that they do not understand the marking criteria or the comments that they receive on their assignments as a feedback on their performance.

\section{Types of Rubrics}

Rubrics can be categorized in two ways: Analytic or Holistic, and General or Task-specific.

\subsection{Analytic or Holistic}

In an analytic rubric, each dimension or criterion is evaluated separately, whereas in a holistic rubric, all dimensions are evaluated simultaneously. Although analytic rubrics are good for formative assessments, it takes more time to score tasks compared to holistic rubrics. On the other hand, scoring can be faster with holistic rubrics, and this type of rubric is also suitable for summative assessments. Nevertheless, holistic rubrics provide a single overall score that fails to provide clear information about where or how improvements can be achieved by the 
users. Though both types of rubrics can be used for classroom purposes, most educators recommend analytic rubrics for effective assessments. Analytic rubrics focus on one criterion at a time and provide detailed feedback to students about their strengths and weaknesses on each task component, which can be helpful for future improvements.

\subsection{General or Task-specific}

General rubrics are those that instructors can use not only for one particular task but for different types of tasks. General rubrics reflect general rather than task-specific features for the descriptions and criteria of a learning outcome. General rubrics highlight the basic knowledge and skills that students need to acquire to accomplish certain learning outcomes. Hence, general rubrics help students acquire knowledge and skills that will be useful in solving many similar tasks. However, task-specific rubrics are designed for a specific task or assignment. In these rubrics, detailed characteristics of each dimension are given for a specific task; thus, scoring student performance with a task-specific rubric is more reliable and faster. However, unlike general rubrics, task-specific rubrics are not shared with students prior to submitting the grades; hence they do not foster student learning.

\section{Constructing a Rubric}

Teachers who regularly use rubrics in their class can prepare a rubric in less than an hour; however, beginners creating the first rubric may take more time. According to Stevens and Levi (2005b), rubrics can be divided into four basic parts: [1] Task description, [2] Scale, [3] Dimensions and [4] Description of dimensions.

\subsection{Task Description}

This refers to the guidelines provided by the instructor regarding how to complete a task. Usually task descriptions are extracted from the syllabus and added on the top of a rubric. This helps students to quickly read the task descriptions as they are handed the rubric and get a quick idea of what are the necessary steps they need to follow to complete a particular task or assignment.

\subsection{Scale}

The scale in a rubric indicates the different levels of performance for grading. Instructors use the rubric scale to determine how well or poorly a particular task has been completed by students. Beginners who try to construct a rubric often use three levels of performance but later expand it to five. In a rubric scale, various terms can be used to describe various levels of performance.

Listed below are some commonly used terms in a rubric scale to explain the different levels of performance compiled by Huba and Freed (2000):

- $\quad$ High level; Middle level; Beginning level.

- Sophisticated; Competent; Partly competent; Not yet competent.

- Distinguished; Proficient; Intermediate; Novice.

- Accomplished; Average; Developing; Beginning.

\subsection{Dimensions}

An instructor breaks down each task or assignment into different dimensions and assigns a weight to each of the various dimensions. By allocating different points or percentages to each dimension, the relative importance of each component is emphasized. It helps students understand what the different parts are in a given task and how much weight is assigned by the teacher to each part of the task. In a rubric, dimension represents the skills that students must display when solving a particular task, such as firm grasp of the concept, use of statistical techniques, proper citations, use of appropriate language, etc. A well-written instructional rubric will not merely outline the skills that students need to master but also highlight the mistakes they can make, which can eventually lead to greater student learning and improvement in the quality of their work.

\subsection{Description of Dimensions}

After breaking down the task into different levels of dimension, the instructor needs to provide a description of each dimension. The description of dimension indicates the various skills and knowledge that students must showcase to achieve a particular learning outcome. For instructors designing a rubric for the first time, description of dimension must state, at the very least, what level of proficiency and skills represent the best level of performance. For example, if the dimension is "presentation skills," the description of dimension for an excellent score in presentation skills could be as follows: "the presenter speaks clearly and loudly, uses regular eye contact, a lively tone, good gestures and body language and engages the audience." [See Appendix- Table A1 and Table A2] 


\section{Benefits of Using Rubrics}

\subsection{Notifies Students of Expectations}

Instructors can use rubrics to note the various degrees of expectations they have by setting certain evaluation criteria for solving a task. Evaluation criteria are the factors that instructors will consider when determining the quality of a task completed by students. Every component of the evaluation criteria is further explained in detail so that students can clearly understand what are the specific skills, knowledge or techniques they need to acquire a particular score or grade. Rubrics can also help instructors spell out the unspoken expectations for a given task in a more explicit manner, such as the use of appropriate citations to avoid plagiarism.

\subsection{Provides Informative and Timely Feedback}

Instructors can use rubrics to provide informative feedback on students' work by highlighting the strengths and weaknesses and by identifying areas for improvement. Breaking up the assignment into distinct dimensions and providing a quick overview of the students' strengths and weaknesses in each dimension provides detailed feedback to the students regarding how well or poorly they have completed a task. In addition, rubrics are also useful for providing quick feedback: they can save grading time of assignments, which can then lead to a timely feedback to students about their performance.

\subsection{Helps to Maintain Grading Consistency and Fair Assessment}

Often instructors who need to correct a large number of papers within a short time worry that all papers may not be graded consistently. Grading consistency is sometimes difficult to maintain due to fatigue, shift in prior expectations and intrusion of external events that can influence an instructor's mood or thinking process. Rubrics can be used as a standard scoring tool to reduce grading inconsistencies. Furthermore, rubrics can also save grading time, as instructors use rubrics to assign a particular score, rather than having to write long comments on each assignment. Hence rubrics can be used to assess students' work in a more efficient and transparent manner. Rubrics can also help teachers provide proper justifications to external parties, such as parents or university authorities, as to why a particular student received a certain score or grade on a specific task.

\subsection{Fosters Student Learning and Self-Assessment}

Although rubrics are useful for grading and providing quick feedback on student performance, they can also serve as an instructional tool to facilitate student learning. By incorporating rubrics in various classroom assignments, instructors can force the students to become active learners and take greater responsibility for their own learning (Stevens \& Levi, 2005a). Instructors can provide the rubrics with the assignments, which can help students, conceptualize their learning targets and monitor their own progress. Rubrics allow students to realize what quality of standards they need to maintain for achieving a specific score or grade. Students can also use rubrics for self-assessment purpose: students can grade their own work by using rubrics before submitting the final version of their work to the teacher. Hence, rubrics can have a powerful effect on student learning, as they can help students improve their writing skills, critical thinking, and analytical abilities and enhance creativity.

\section{Research Findings on the Use of Rubrics}

The use of rubrics in the classroom allows students to understand what is meant by an acceptable level of performance when performing a given task. Effective rubrics also help students to realize the extent to which their current performance meets each criterion of importance and what future steps can be taken to enhance the quality of their work. Although rubrics are useful for grading and assessment, many authors claim that well-designed rubrics can also be used as an instructional tool to facilitate student learning. Below we have provided a summary of some of the previous research findings on rubrics in a variety of disciplines in higher education.

While some researchers, such as Campbell (2005) and Tunon and Brydges (2006), noted the benefits of using rubrics for evaluative purposes, Song (2006) argued that rubrics can provide constructive feedback which can help students identify areas for improvement. Nevertheless, Andrade (2005) claimed that instructors can use rubrics as a teaching tool to promote active learning in the classroom. Rubrics help to clarify targets for students' work, help students regulate their progress and make grading more fair and transparent.

A study conducted by Bolton (2006) on 150 business students using rubrics in class indicated that rubrics helped students understand the critical issues in solving their assignments, helped to evaluate their own performance and provided immediate feedback on their strengths and weaknesses. A similar study was conducted by Andrade and $\mathrm{Du}$ (2005), who interviewed 14 undergraduates after they used rubrics in class for solving assignments. Most of the students responded by saying that rubrics helped them produce higher quality work and to score better marks in the assignment. A qualitative analysis of rubrics based on questionnaires and interviews was conducted by Powell 
(2001). Rubrics were used by the students for solving assignments in class and for self-grading purposes (Andrade $\&$ Reddy, 2010). Findings from the research indicate that students using rubrics experienced greater satisfaction and learning. A study conducted by Schneider (2006) used two rubrics in a class of 55 undergraduate students. The first rubric was provided to the students after submission of grades, while the second was provided with assignments before grading. Findings indicate that the second rubric, which was submitted with assignment, was rated as useful by $88 \%$ of the students. On the other hand, the first rubric, which was provided after grading, was rated as useful by only $10 \%$ of the students. Petkov and Petkova (2006) conducted a similar study in a post-graduate level course. They used two groups of students, where one group was provided with a rubric with the project at the beginning of the semester, while the other group was not provided with a rubric. Later, a comparison of student grades across both groups indicate that the group that used rubrics achieved significantly higher grades compared to the students in another group that did not use rubrics. Reitmeier, Svendsen, and Vrchota (2004) conducted a survey in which they used rubrics in a food preparation course. Students were required to self- and peer-assess a minimum of four oral presentations over the course of a semester. Findings showed that students using rubrics achieved an average score of $94 \%$, which is higher than the average score of $86 \%$ achieved by students in the previous semester that did not use rubrics.

Although most of the researchers proved the instructional benefits of using rubrics in the classroom, there were some researchers that noted that rubrics really do not make any difference to student learning or teaching. Parkes (2006) conducted an experimental research and examined the impact of music performance rubrics on grading satisfaction. Findings indicated that there were no significant differences in the attitude of students and teachers after the use of rubrics. A similar study by Green and Bowser (2006) reported contrasting findings. They used rubrics to evaluate the Master's thesis literature in a two-group post-test design. A t-test was conducted comparing the mean scores of students with and without rubrics. Findings showed that there were no significant differences between mean scores of these papers written with and without rubrics.

\section{Conclusion}

Today rubrics are utilized in the classroom as an instructional tool across a wide range of disciplines; nevertheless, the number of teachers using rubrics remains small. Although the use of rubrics has become popular in assessing various performance-based tasks, many educators remain unaware of rubrics and their enormous benefits. Most teachers often tend to use their personal judgment in evaluating students' performance, a judgment that can be inconsistent and even biased. Sometimes students complain that they are assessed unfairly by teachers and that they deserve to get higher marks. Hence for instructors it is important to communicate their assessment philosophy to their students by using rubrics when giving any task in the class. With the help of rubrics, students can clearly understand what it takes to obtain an "A" grade in a particular assignment or task. At times, students beg their teachers for a few extra marks, but with a rubric, a teacher can easily point to the rubric and say, "See, this is where you fell short." Hence rubrics can serve as a valuable grading tool that can lead to consistent, fair and more transparent grading.

Students can often fail to achieve a good grade if they are confused about what it takes to achieve that grade in a particular task. In this respect, rubrics can help teachers clarify their pedagogical goals to their students. Students can learn more from rubrics than they can from a single letter grade. As rubrics can be used to identify pertinent aspects of a piece of writing, they can be used by instructors to communicate expectations very clearly. Students may come from various backgrounds; hence some are often confused as to what skills they need in order to achieve high scores or marks. In this respect, rubrics provide all students in the class with clear guidelines regarding what expectations they must fulfill to achieve a good grade.

However, rubrics should not merely be used as a scoring tool: a well-designed rubric can also make enormous contributions to the quality of a student's education. Rubrics can help students conceptualize their learning targets and monitor their own progress. Rubrics can be used by students as part of a formative assessment for continuous tasks, which can help students regularly assess the quality of their own work and make improvements accordingly.

Moreover, rubrics can provide students with concrete feedback on their strengths and weaknesses. By using rubrics, students can analyze their own work and decide to what extent it lives up to the standards set out by their teacher in the rubric. Most parents also appreciate the use of rubrics in the class because they provide detailed and clear feedback regarding their children's work. Therefore, rubrics can make justifying student scores to parents or respective authorities much easier for the teachers (Andrade, 2000).

Although many researchers have noted the benefits of using rubrics in the classroom, there are some who have criticized rubrics for limiting teachers' judgment and, hence, the learning process (Turley \& Gallagher, 2008; Wolf \& Stevens, 2007). According to Kohn (2006), rubrics can standardize teachers' judgment regarding student 
performance. Wolf and Stevens (2007) point out that students who regularly use rubrics may begin to think that if something is not stated in the rubric, then it is not an important part of the assessment. According to Turley and Gallagher (2008), rubrics can be vague and unclear, which can result in different interpretations by different users.

Nevertheless, most educators today do agree that rubrics can make assessing student work more efficient, consistent, objective and transparent. Teachers can easily use rubrics to evaluate whether a student's work is excellent, mediocre or in need of further improvement. Initially, instructors may hesitate to utilize rubrics in the classroom, as they can require an investment of valuable time, however, once a rubric is constructed, it can pay great dividends in the form of decreased grading time for the instructor, more constructive feedback on student performance and enhanced student learning.

\section{References}

Andrade, H. G. (2005). Teaching with Rubrics: The Good, the Bad, and the Ugly. College Teaching, 53(1), 27-30. https://doi.org/10.3200/CTCH.53.1.27-31

Andrade, H., \& Du, Y. (2005). Student perspectives on Rubric-referenced Assessment. Practical Assessment, Research \& Evaluation, 10(5), 1-11.

Arter, J., \& McTighe, J. (2001). Scoring rubrics in the classroom: Using performance criteria for assessing and improving student performance. Thousand Oaks, CA: Corwin Sage.

Bolton, C. F. (2006). Rubrics and Adult learners: Andragogy and assessment. Assessment Update, 18(3), 5-6.

Campbell, A. (2005). Application of ICT and rubrics to the assessment process where Professional judgment is involved: The features of an E-marking tool. Assessment \& Evaluation in Higher Education, 30(5), 529-537. https://doi.org/10.1080/02602930500187055

Green, R., \& Bowser, M. (2006). Observations from the field: Sharing a Literature Review Rubric. Journal of Library Administration, 45(1-2), 185-202. https://doi.org/10.1300/J111v45n01_10

Huba, M. E., \& Freed, J. E. (2000). Learner-centered assessment on college campuses: shifting the focus from teaching to learning. Boston, Allyn and Bacon.

Jonsson, A., \& Svingby, G. (2007). The use of Scoring rubric: Reliability, validity and educational consequences. Educational Research Review, 2, 130-144. https://doi.org/10.1016/j.edurev.2007.05.002

Kohn, A. (2006). The Trouble with Rubrics. Engl J, 95(4), 12-15. https://doi.org/10.2307/30047080

Parkes, K. A. (2006). The effect of performance rubrics on college level applied studio grading ( $\mathrm{PhD}$ diss, University of Maimi).

Penny, J., Johnson, R. L., \& Gordon, B. (2000). Using Rating Augmentation to expand the Scale of an Analytic rubric. Journal of Experimental Education, 68(3), 269-287. https://doi.org/10.1080/00220970009600096

Petkov, D., \& Petkova, O. (2006). Development of Scoring Rubrics for IS Projects as an Assessment Tool. Issues in Informing Science and Information Technology, 3, 499-510.

Powell, T. A. (2001). Improving assessment and evaluation methods in film and television production courses (PhD diss, Capella University).

Reitmeier, C. A., Svendsen, L. K., \& Vrchota, D. A. (2004). Improving Oral Communication skills of students in Food science courses. Journal of Food Science Education, 3, 15-20. https://doi.org/10.1111/j.1541-4329.2004.tb00036.x

Schneider, J. F. (2006). Rubrics for Teacher education in Community college. The Community College Enterprise, 12(1), 39-55.

Silvestri, L., \& Oescher, J. (2006). Using rubrics to increase the Reliability of Assessment in health classes. International Electronic Journal of Health Education, 9, 25-30.

Song, K. H. (2006). A Conceptual model of Assessing teaching performance and Intellectual development of Teacher candidates: A pilot study in the US. Teaching in Higher Education, 11(2), 175-190. https://doi.org/10.1080/13562510500527701

Tunon, J., \& Brydges, B. (2006). A study on using rubrics and Citation analysis to measure the quality of Doctoral dissertation reference lists from traditional and nontraditional institutions. Journal of Library Administration, 45(3-4), 459-481.

Turley, E. D., \& Gallagher, C. G. (2008). On the Uses of rubrics: Reframing the great rubric Debate. Engl J, 79(4), 
87-92.

Wilson, M. (2007). Why I won't be using Rubrics to respond to Students' writing. Engl J, 96(4), 62-66. https://doi.org/10.2307/30047167

Wolf, K., \& Stevens, E. (2007). The Role of rubrics in Advancing and Assessing student learning. The Journal of Effective Teaching, 7(1-2), 3-14.

\section{Appendix}

\section{Table A1. The four basic parts of a Rubric}

[1] TASK DESCRIPTION: Students are required to write an essay on the topic "Today the education quality is not as good as it was 5 years back". The students must write the essay within 1500 words. The essay should include facts, evidence or personal experiences to showcase creativity, conceptual understanding and analytical abilities.

\begin{tabular}{|l|l|l|l|l|}
\hline [2] SCALE & Sophisticated & Competent & $\begin{array}{l}\text { Partly } \\
\text { competent }\end{array}$ & $\begin{array}{l}\text { Not yet } \\
\text { competent }\end{array}$ \\
\hline $\begin{array}{l}\text { [3]DIMENSIONS } \\
\text { Depth of analysis }\end{array}$ & $\begin{array}{l}\text { [4] DESCRIPTION OF DIMENSIONS } \\
\text { The author goes beyond the basic } \\
\text { requirements of the assignment and } \\
\text { explores the implications and evidence in } \\
\text { new light using original thinking. }\end{array}$ & & \\
\hline $\begin{array}{l}\text { Grasp of the } \\
\text { concepts }\end{array}$ & & & & \\
\hline Paragraph writing & & & & \\
\hline Use of evidence & & & & \\
\hline Conclusion & & & & \\
\hline
\end{tabular}

\section{Table A2. Sample of a Completed Rubric}

Students are required to write an essay on the topic "Today the education quality is not as good as it was 5 years back". The students must write the essay within 1500 words. The essay should include facts, evidences or personal experiences to showcase creativity, imagination and conceptual abilities in writing.

\begin{tabular}{|c|c|c|c|c|}
\hline & $\begin{array}{l}\text { Sophisticated } \\
(80-100 \text { points })\end{array}$ & $\begin{array}{c}\text { Competent } \\
(70-79 \text { points })\end{array}$ & $\begin{array}{c}\text { Partly competent } \\
(50-69 \text { points })\end{array}$ & $\begin{array}{l}\text { Not yet competent } \\
\text { (less than } 50 \text { points) }\end{array}$ \\
\hline $\begin{array}{l}\text { Depth of } \\
\text { analysis } \\
(10 \%)\end{array}$ & $\begin{array}{l}\text { The author goes beyond } \\
\text { the basic requirements of } \\
\text { the assignment and } \\
\text { explores the implications } \\
\text { and evidence in new light } \\
\text { using original thinking. }\end{array}$ & $\begin{array}{l}\text { The author fully } \\
\text { meets the basic } \\
\text { parameters of the } \\
\text { assignment. The } \\
\text { paper demonstrates a } \\
\text { good analytical } \\
\text { study but does not } \\
\text { provide new } \\
\text { insights. }\end{array}$ & $\begin{array}{l}\text { The author fails to } \\
\text { address some } \\
\text { aspects of the } \\
\text { assignment. } \\
\text { Demonstrates } \\
\text { some analytical } \\
\text { skills but not } \\
\text { clearly. }\end{array}$ & $\begin{array}{l}\text { The author fully fails } \\
\text { to address the basic } \\
\text { aspects of the } \\
\text { assignment. }\end{array}$ \\
\hline $\begin{array}{l}\text { Grasp of } \\
\text { the } \\
\text { concepts } \\
(20 \%)\end{array}$ & $\begin{array}{l}\text { The paper represents the } \\
\text { arguments, evidence and } \\
\text { conclusions accurately, } \\
\text { fairly and eloquently. } \\
\text { Demonstrates a firm } \\
\text { understanding of the } \\
\text { concepts. }\end{array}$ & $\begin{array}{l}\text { Paper represents all } \\
\text { the arguments, } \\
\text { evidence and } \\
\text { conclusions } \\
\text { accurately. }\end{array}$ & $\begin{array}{l}\text { Paper represents } \\
\text { the authors' } \\
\text { arguments, } \\
\text { evidence and } \\
\text { conclusions } \\
\text { accurately but not } \\
\text { sufficiently } \\
\text { clearly. }\end{array}$ & $\begin{array}{l}\text { The paper fails to } \\
\text { present the arguments, } \\
\text { evidence and } \\
\text { conclusions. }\end{array}$ \\
\hline $\begin{array}{l}\text { Paragraph } \\
\text { writing } \\
(30 \%)\end{array}$ & $\begin{array}{l}\text { All the paragraphs of the } \\
\text { paper very well written. } \\
\text { Guides the reader }\end{array}$ & $\begin{array}{l}\text { Paragraphs are well } \\
\text { written in a good } \\
\text { format. It provides }\end{array}$ & $\begin{array}{l}\text { The paragraph } \\
\text { demonstrates the } \\
\text { arguments and }\end{array}$ & $\begin{array}{l}\text { Paragraph does not } \\
\text { have a discernible } \\
\text { central argument and }\end{array}$ \\
\hline
\end{tabular}




\begin{tabular}{|c|c|c|c|c|}
\hline & $\begin{array}{l}\text { smoothly and logically } \\
\text { into the body of the paper. }\end{array}$ & $\begin{array}{l}\text { the reader some idea } \\
\text { of the evidence that } \\
\text { will follow. }\end{array}$ & $\begin{array}{l}\text { evidence, though } \\
\text { not stated } \\
\text { sufficiently } \\
\text { clearly. }\end{array}$ & $\begin{array}{l}\text { is not well written and } \\
\text { structured. }\end{array}$ \\
\hline $\begin{array}{l}\text { Use of } \\
\text { evidence } \\
(30 \%)\end{array}$ & $\begin{array}{l}\text { Strong evidence are used } \\
\text { to support the arguments. } \\
\text { In providing evidence } \\
\text { appropriate illustrations } \\
\text { and quotations are used. } \\
\text { The connection between } \\
\text { argument and evidence is } \\
\text { clearly articulated in all } \\
\text { cases. }\end{array}$ & $\begin{array}{l}\text { Some evidence used } \\
\text { to support the } \\
\text { arguments, though } \\
\text { not rich or detailed. } \\
\text { In some cases the } \\
\text { connection between } \\
\text { argument and } \\
\text { evidence is not clear. }\end{array}$ & $\begin{array}{l}\text { Strong evidence } \\
\text { are not provided to } \\
\text { support } \\
\text { arguments. The } \\
\text { connection } \\
\text { between argument } \\
\text { and evidence not } \\
\text { clearly articulated } \\
\text { in most cases. }\end{array}$ & $\begin{array}{l}\text { Failed to provide } \\
\text { sufficient evidence to } \\
\text { support the } \\
\text { arguments. }\end{array}$ \\
\hline $\begin{array}{l}\text { Conclusion } \\
(\mathbf{1 0} \%)\end{array}$ & $\begin{array}{l}\text { The conclusion provides } \\
\text { suggestions or raises } \\
\text { questions relevant to the } \\
\text { central argument. The } \\
\text { author synthesizes and } \\
\text { reframes key points from } \\
\text { main paragraphs. } \\
\text { Elegantly concludes the } \\
\text { paper with a hint of new } \\
\text { insights. }\end{array}$ & $\begin{array}{l}\text { The author } \\
\text { synthesizes key } \\
\text { issues and brings a } \\
\text { good closure but } \\
\text { does not examine } \\
\text { new perspectives or } \\
\text { questions. }\end{array}$ & $\begin{array}{l}\text { Repeats the same } \\
\text { points from the } \\
\text { main paragraph } \\
\text { without reframing } \\
\text { them. Provides a } \\
\text { conclusion that } \\
\text { fails to raise any } \\
\text { curiosity. }\end{array}$ & $\begin{array}{l}\text { Repeats the topics } \\
\text { from the main } \\
\text { paragraphs very } \\
\text { frequently and fails to } \\
\text { provide a good } \\
\text { ending. }\end{array}$ \\
\hline
\end{tabular}

\section{Copyrights}

Copyright for this article is retained by the author(s), with first publication rights granted to the journal.

This is an open-access article distributed under the terms and conditions of the Creative Commons Attribution license (http://creativecommons.org/licenses/by/4.0/). 